\title{
Investigation of the behavior of a heating system coupled to parabolic trough solar collector system
}

\author{
Abdellah Mellaikhafi ${ }^{*}$, Amine Tilioua ${ }^{1}$, Mohamed Hajjaj $^{2}$, Abella Bouaaddi $^{2}$, and Choukri Messaoudi ${ }^{3}$ \\ ${ }^{1}$ Research Team in Thermal and Applied Thermodynamics (2.T.A.), Mechanics, Energy Efficiency and Renewable Energies \\ Laboratory (L.M.3.E.R.), Department of Physics, Faculty of Sciences and Techniques Errachidia, Moulay Ismaïl University of \\ Meknès, B.P. 509, Boutalamine, Errachidia, Morocco. \\ ${ }^{2}$ Laboratory Engineering Energy, Materials and Systems, Department of Physics, National School of Applied Sciences, Ibn Zohr \\ University Agadir, 80000, Morocco. \\ ${ }^{3}$ OETAT, Department of Physics, Faculty of Sciences and Techniques Errachidia, Moulay Ismail University of Meknès, B.P. 509 \\ Boutalamine Errachidia, Morocco.
}

\begin{abstract}
The objective of this work is to study the thermal behavior of a solar heating system using an active layer, integrated in a wall and supplied with hot water by a parabolic trough solar collector (PTC). The prototype includes a PTC collector with a surface area of $1.8 \mathrm{~m}^{2}$, a tank and an active layer integrated in a wall. A complete simulation model using the TRNSYS 16 simulation software has been established. Simulation tests under the climatic conditions of the city of Errachidia located in southeastern Morocco show the temperature variations in the different components of the installation as well as the useful energy gained during the three coldest months (December, January and February). In addition, an evaluation study of the system's performance with effect of different values of the reflectivity of PTC collector mirror was carried out. The results obtained show that the PTC efficiency increased from 0.41 to 0.63 when the reflectivity of the collector mirror increased from 0.6 to 0.9 for the three heating months.
\end{abstract}

Keywords: PTC, active layer, solar heating system, TRNSYS 16

\footnotetext{
* Corresponding author: abd.mellaikhafi@gmail.com
} 


\section{Introduction}

The exploitation of solar energy in the building sector is experiencing increasing demand due to low operating costs and government support for the deployment of renewable energy. The thermal energy used in buildings is mainly produced by converting solar radiation into thermal energy transmitted by a heat-transfer fluid, using solar collectors. This gained thermal energy from the heat transfer fluid can be used for space heating using radiators, underfloor heating or wall heating. However, the current researches on thermal behavior and performance of solar heating systems were based on experimental and simulation studies. In this context, Mehdaoui et al. [1] presented an optimal dimensioning of active layer solar heating system integrated in the floor and in the wall. The water heating was done using flat plate solar collectors. The authors performed simulations using TRNSYS 16 software and developed an experimental device. The results obtained revealed that $6 \mathrm{~m}^{2}$ of flat plate solar collector area, $120 \mathrm{Kg} \cdot \mathrm{h}^{-1}$ collector mass flow rate and 450 liters of hot water storage tank capacity are the good values to optimize the system performance. A solar heating system composed of a PTC, an absorption heat pump and an oil/water heat exchanger has been the subject of a performance analysis performed by Fan et al [2]. The authors have shown that the collector efficiency under different weather conditions is variable between 40 and 55\%. Chen et al. [3] have shown that the thermal efficiency of a small solar heating system composed of a solar PTC and ventilation pipes for active solar heating of houses in winter was higher than $60 \%$ for a generally insulated room located at $39.87^{\circ}$ latitude. A numerical, experimental and economic investigation of a solar floor heating system using solar collectors for a traditional bathroom (Hammam) has been carried out by Sobhy et al. [4]. The authors revealed that the system without thermal storage achieves the desired temperature on sunny winter days between $30^{\circ} \mathrm{C}$ and $37^{\circ} \mathrm{C}$. For cold zones, Yang et al. [5] have presented a performance analysis of the radiant floor heating system using models established in MATLAB/Simulink. A new design of solar district heating plants with a field of flat plate and PTCs installed in Taars, Denmark, was realized by Tian et al [6]. The measured and simulated annual thermal performance of the solar heating plant was analyzed for the full year from September 2015 to August 2016. The authors concluded that in case the defocusing of PTCs is avoided, the potential annual thermal performance of the solar heating system can reach $5180 \mathrm{MWh}$ (518 $\mathrm{kWh} / \mathrm{m}^{2}$ ) with a solar fraction of $24 \%$. S. Sobhansarbandi et al [7] investigated the possibility of using compound parabolic concentration (CPC) solar collectors instead of planar collectors (FPCs) to explore the feasibility of reducing the surface area required by the collectors. Their system is composed of solar thermal collectors, a storage tank and water circulation to transport heat to four similar floor slabs. The simulation results obtained showed that a $2 \mathrm{~m}^{2}$
CPC collector system can operate satisfactorily to correspond to an $8 \mathrm{~m}^{2} \mathrm{FPC}$ system, the required water circulation temperature in the slabs is the same for both cases. Two studies have been realized by Halimi et al $[8,9]$, the first one is concerned with the technical feasibility of a PTC system to predict the captured solar energy for different orientations and tracking modes under climate conditions of Errachidia city in south eastern Morocco. The second is an experimental study of a PTC solar equipped with a U-shaped absorber for normal incidence radiation. Besides, L. Li et al [10] studied a passive solar heating system, combining the hot air supply system and the radiant floor system. The authors used simulation models developed to analyze the performance of this heating system and to verify the optimal solar heating system. The indoor operating temperature varies from 18.0 to $20.9^{\circ} \mathrm{C}$, and the average night temperature is $18.9^{\circ} \mathrm{C}$. Furthermore, an analytical model was proposed by $\mathrm{Z}$. Yin et al [11] to establish a hybrid heating system. The system consists of a solar collector, an air-source heat pump and a water tank, the aim is to maximize the overall energy conversion efficiency of the system. During the day, the solar collector is activated at full capacity. However, the water tank initially gives off heat during the night, which allows the heat pump to operate to compensate for the insufficient part. The authors deduced that such a system can reduce electricity consumption by $33 \%$ compared to a traditional heating system. Moreover, the thermal performance and economic analysis of a heating system for buildings in rural areas composed of an evacuated tube solar collector with auxiliary electric heating has been investigated by L. Yanhua et al [12]. The results obtained show that the indoor air temperature in the heating room can satisfy the heating demand. Moreover, a solar heating prototype consisting of a flat plate solar collector, a solar hot water tank and an active layer integrated in a single piece was developed by F. Mehdaoui et al [13] to meet the air heating needs of Tunisian households. The simulation results of the TRNSYS software showed, on the one hand, that the average solar fraction obtained is about $84 \%$ for an annual solar insolation of about $6493.37 \mathrm{MJm}^{-2}$, and on the other hand, that the relative humidity indoors is reduced by about $40 \%$.

The objective of this work is to investigate the performance and behavior of a solar heating system with an active layer integrated in the wall (heating wall), supplied with hot water from a PTC solar as shown in Fig. 1. Our system includes a pump and a storage tank. The heating wall is perfectly fixed on a box in order to heat its interior air. The internal volume of the box is $1 \mathrm{~m} 3$ and all its walls are adiabatic.

The methodology to conduct the work is to first evaluate the thermal and energetic performances of our system for the three coldest months (December, January and February) in the city of Errachidia located in the southeast of Morocco. Secondly, we study the effect of the reflectivity of the PTC mirror on the performance of the system. 


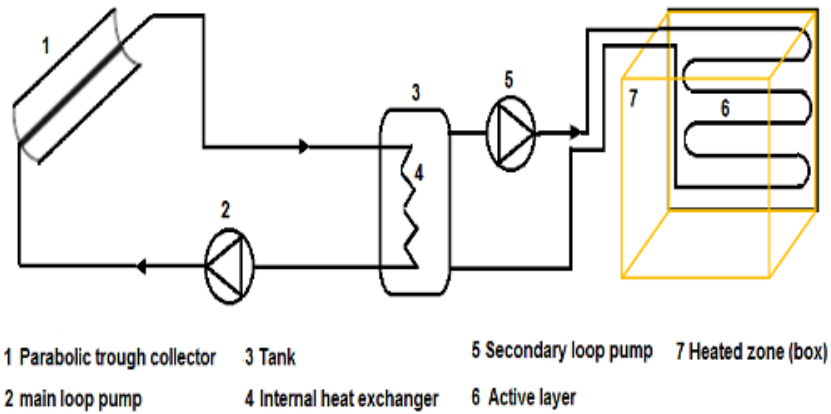

Fig. 1. Diagram of heating prototype

\section{Methods}

The thermal behavior of the heating system of a wall heating system supplied with hot water from a PTC solar collector was simulated by TRNSYS 16 software. Mathematical models which describe the physical behavior of each system component are formulated in a FORTRAN code implanted in TRNSYS. In this work, the TRNSYS model presented in Fig.2. The initial simulation temperatures of the water in the different prototype components and the air inside the heated zone (chamber) are measured experimentally. Meteorological data of Errachidia city are generated by Meteonorm 7 software. The different components of the prototype are presented in Table 1.

Table 1. Main types and parameters of TRNSYS model

\begin{tabular}{|c|c|}
\hline Type & Object and main parameters \\
\hline $\begin{array}{l}\text { Type 109- } \\
\text { TMY2 }\end{array}$ & $\begin{array}{l}\text { Object: } \\
\text { Data Reader and Radiation Processor } \\
\text { Main parameters: } \\
\text { Reading meteorological data of the city of } \\
\text { Errachidia, Morocco. }\end{array}$ \\
\hline Type 536 & $\begin{array}{l}\text { Object: } \\
\text { Linear Parabolic Concentrator Solar } \\
\text { Collector(Parabolic trough concentrator) } \\
\text { Main parameters: } \\
\text { Number: } 1 \text { collecter } \\
\text { Proprieties of collector (see Table II) }\end{array}$ \\
\hline Type 60d & $\begin{array}{l}\text { Object: } \\
\text { Storage Tank: Fixed Inlets, Uniform Losses } \\
\text { and Node Heights } \\
\text { Main parameters: } \\
\text { Tank volume: } 50 \mathrm{~L} \text {, } \\
\text { tank height: } 0.5 \mathrm{~m} \text {, } \\
\text { number of tank nodes: } 2 \text {. }\end{array}$ \\
\hline Type 114 & $\begin{array}{l}\text { Object: } \\
\text { Single Speed Pump } \\
\text { Main parameters: } \\
\text { Rated flow rate: } 126 \mathrm{~kg} / \mathrm{h} \text {; Rated power: } 43 \mathrm{~W} \text {; }\end{array}$ \\
\hline Type 56 & $\begin{array}{l}\text { Object: } \\
\text { Multi-Zone Building } \\
\text { Main parameters: } \\
\text { Volume }: 1 \mathrm{~m}^{3} ; \\
5 \text { adibatic walls }\end{array}$ \\
\hline
\end{tabular}

\begin{tabular}{|c|c|}
\hline & $\begin{array}{l}1 \text { wall with an active layer. } \\
\text { The temperature of the air inside the box is } \\
\text { not controlled. }\end{array}$ \\
\hline Type $2 b$ & $\begin{array}{l}\text { Object: } \\
\text { ON/OFF Differential Controller } \\
\text { Main parameters: } \\
\text { High limit cut-out: } 100 \mathrm{C} ;\end{array}$ \\
\hline Type 709 & $\begin{array}{l}\text { Object: } \\
\text { Circular Fluid-Filled Pipe } \\
\text { Main parameters: } \\
\text { Inside diameter: } 0.012 \mathrm{~m} \text {; } \\
\text { Pipe length: } 3 \mathrm{~m} \text {; } \\
\text { Pipe thermal conductivity: } 0.416 \mathrm{~W} /(\mathrm{m} . \mathrm{K})\end{array}$ \\
\hline
\end{tabular}

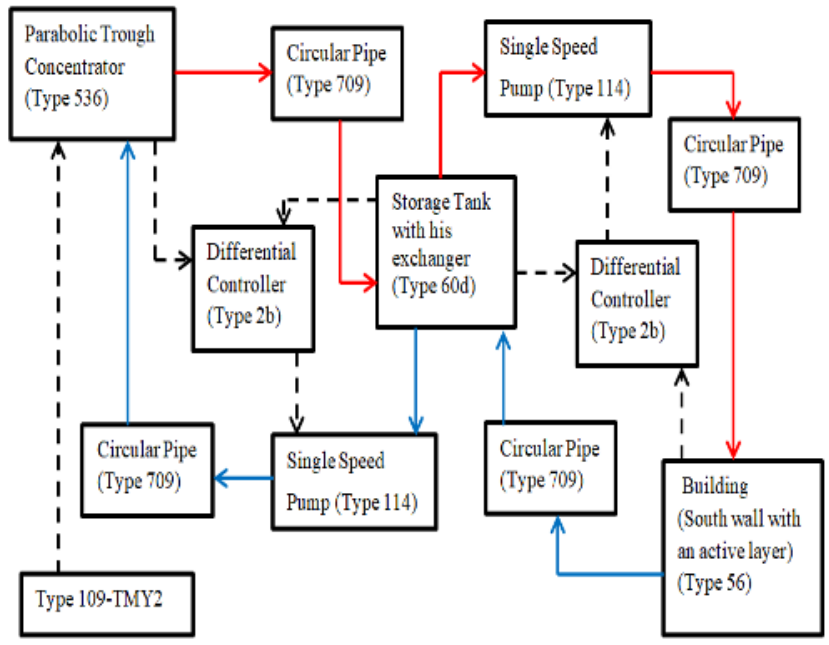

Fig. 2. TRNSYS simulation of studied system

Table 2. Parameters of the parabolic trough collector

\begin{tabular}{|l|l|}
\hline Characteristics & Values \\
\hline Collector length & $2 \mathrm{~m}$ \\
\hline Aperture diameter & $0.9 \mathrm{~m}$ \\
\hline Aperture surface of the collecter & $1.8 \mathrm{~m}^{2}$ \\
\hline Focal distance & $0.19 \mathrm{~m}$ \\
\hline Geometric concentration ratio & 12.5 \\
\hline Interception factor & 0.83 \\
\hline Reflectivity of the Memoir & 0.6 \\
\hline Absorptivity of the absorber tube & 0.9 \\
\hline Emissivity of the absorber tube & 0.09 \\
\hline
\end{tabular}

\section{Results and discussion}

\subsection{System performance evaluation}

The monthly useful heat produced by PTC, the monthly efficiency of PTC and the temperature evolution in the heated zone obtained by the simulation were chosen as analysis indicators for the system performance evaluation. Fig. 3 shows the monthly averages in Watts of the solar beam radiation on the inclined surface of PTC, the monthly useful heat produced by PTC (reflectivity of the mirror is 0.6 ) and 
the heat exchanged between the heat exchanger and the storage tank during the coldest months (December, January and February) in Errachidia. We have noticed that the effective energy gain of the PTC and the heat exchanged between the exchanger and the storage tank differ from month to month. They are greater during the month of January because the solar energy received is greater than in the other two months. The total monthly beam radiation amounts to $294.24 \mathrm{~kW}$ for December, $321.47 \mathrm{~kW}$ for January and $271.34 \mathrm{~kW}$ for February. The total useful heat produced by the PTC and the total heat exchanged between the exchanger and the tank are respectively $117.8 \mathrm{~kW}$ and $101.01 \mathrm{KW}$ for the month of December, $131.26 \mathrm{~kW}$ and $113.4 \mathrm{~kW}$ for the month of January and $271.34 \mathrm{~kW}$ and 112.56 $\mathrm{kW}$ for the month of February. The monthly yield of PTC for the three months (December, January and February) is 0.41 .

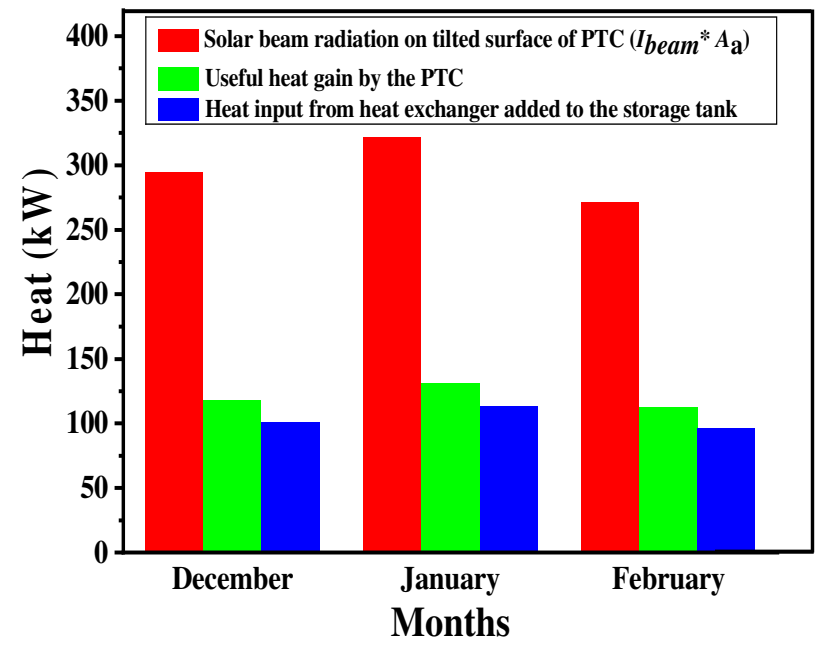

Fig 3. Monthly values of the solar beam radiation on tilted surface of PTC collector, the useful heat produced by PTC and the heat exchanged between an internal heat exchanger.

On the other hand, Fig. 4 shows the variations in the ambient temperature $\left(\mathrm{T}_{\mathrm{amb}}\right)$, the indoor air temperature of the heated area $\left(\mathrm{T}_{\mathrm{box}}\right)$ and the solar beam radiation of tilted surface per $\mathrm{m}^{2}$ ( $\left.\mathrm{I}_{\text {beam }}\right)$ of collector surface during the coldest month (January). We noticed that there is a dependency between the variation of $\mathrm{T}_{\mathrm{box}}$ and the variation of $\mathrm{I}_{\text {beam. }}$. If $\mathrm{I}_{\text {beam }}$ increases $\mathrm{T}_{\text {box }}$ also increases. However, it is less dependent on $\mathrm{T}_{\mathrm{amb}}$ because the box walls are well insulated.

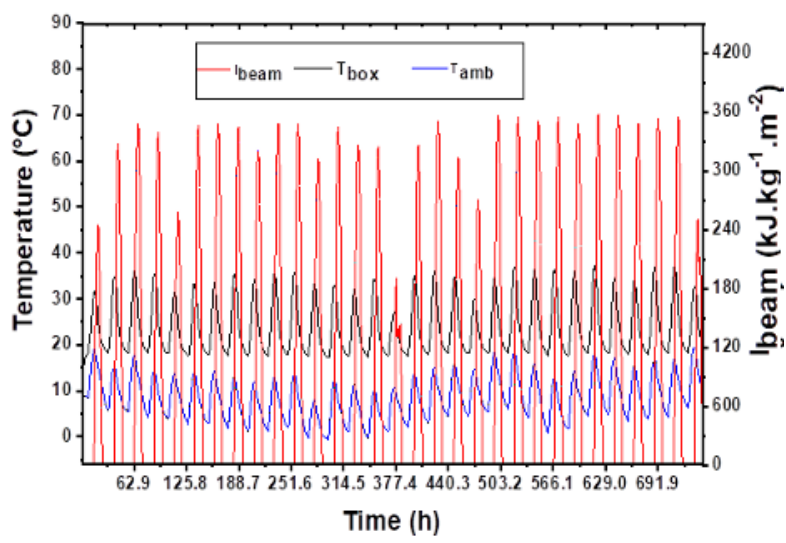

Fig 4. Evolution of the ambient temperature $\left(\mathrm{T}_{\mathrm{amb}}\right)$, the indoor air temperature of the heated zone $\left(\mathrm{T}_{\mathrm{box}}\right)$ and the solar beam radiation of tilted surface ( $\mathrm{I}_{\text {beam}}$ ) per $\mathrm{m}^{2}$ during the month of January.

\subsection{Reflectivity effect of the PTC mirror}

To determine the effect of collector reflectivity on the energy gain of the installation, the simulation by TRNSYS has been performed using the parameters listed in Table 1 and Table 2 . The only parameter that has been varied is the PTC collector reflectivity, taking values from 0.6 to 0.9 . Fig. 5 shows the monthly heat variation (in $\mathrm{KW}$ ) produced by the PTC as a function of collector reflectivity for the three months of simulation.

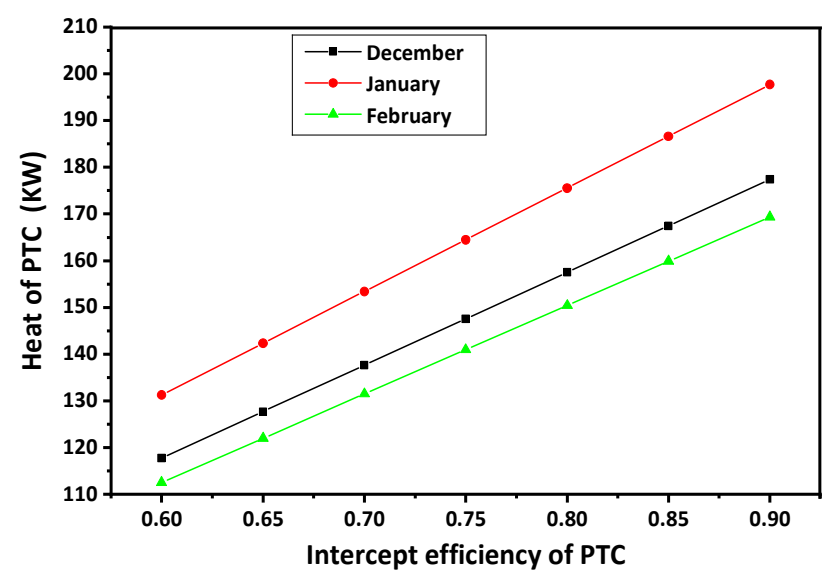

Fig 5. Monthly heat variation produced by the PTC as a function of collector reflectivity for the three months of simulation

The graphical representations are lines not parallel to the ordinate axis (Fig.5), the function f, which represents this variation, is therefore affine of the form $f(x)=a x+b$. For the month of December, the heat gained by PTC improves by the function $\mathrm{f}_{1}(\mathrm{x})=19.85 \mathrm{x}$ +105.88 when the collector reflectivity increases. This heat increases from $117.80 \mathrm{~kW}$ to $177.39 \mathrm{~kW}$ after a change in reflectivity from 0.6 to 0.9 . For the months of January and February the improvement is represented respectively by the functions $\mathrm{f}_{2}(\mathrm{x})=22.14 \mathrm{x}+117.97$ and $f_{3}(x)=18.93 x+101.2$. The heat gained by PTC increases from $131.26 \mathrm{~kW}$ to $197.7 \mathrm{~kW}$ for the month of January and from $112.56 \mathrm{~kW}$ to $169.37 \mathrm{~kW}$ for the month of February after a variation in reflectivity from 0.6 to 0.9 . These latter results are confirmed in Fig. 6 . 
We found that the monthly efficiency of PTC improved significantly from 0.4 to 0.6 for December, 0.41 to 0.67 for January and 0.41 to 0.62 for February, according to the reflectivity ranging from 0.6 to 0.9 .

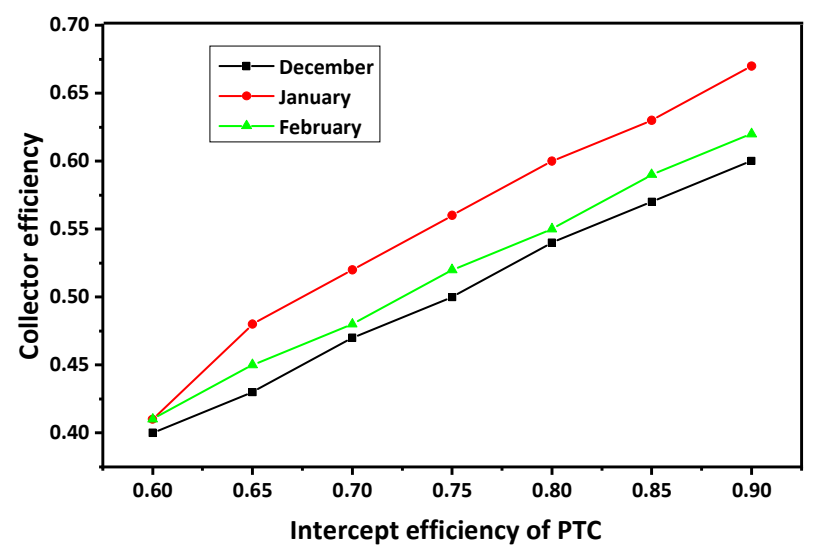

Fig 6. Variation of monthly efficiency of PTC as a function of reflectivity

On the other hand, Fig. 7 shows the variation of the average temperature and the maximum air temperature inside the box as a function of the collector reflectivity during the day of 08 January. We noticed that the daily average temperature increases from $29.03{ }^{\circ} \mathrm{C}$ to 33.58 ${ }^{\circ} \mathrm{C}$, an increase of about $4{ }^{\circ} \mathrm{C}$, and the daily maximum temperature increases from $35.59{ }^{\circ} \mathrm{C}$ to $43.07{ }^{\circ} \mathrm{C}$, an increase of about $6.5{ }^{\circ} \mathrm{C}$, for a variation of reflectivity from 0.6 to 0.9 .

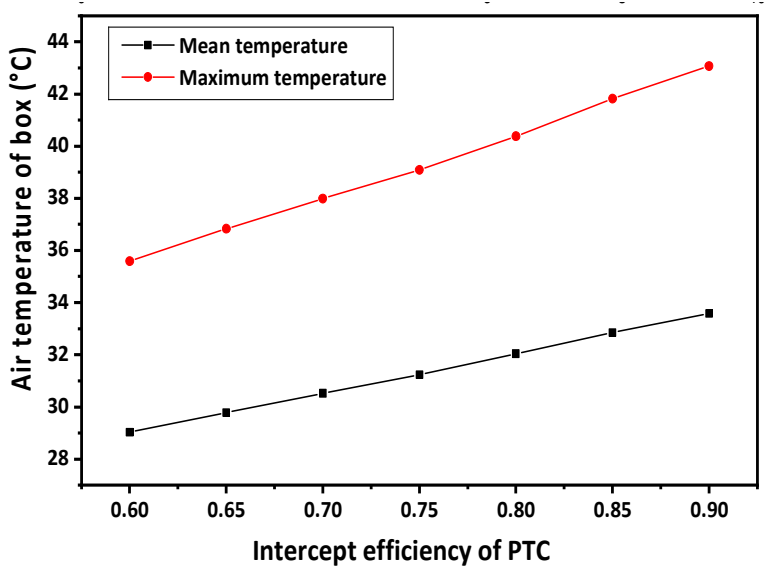

Fig.7. Variation of the average temperature and the maximum temperature of air inside the the heated zone (box) as a function of the collector reflectivity for the day 08 January.

\section{Conclusion}

In this study, the thermal behavior of a solar heating system used for air heating during cold weather was investigated for the city of Errachidia located in southeastern Morocco. The system consists mainly of a parabolic trough solar collector, a storage tank and a box with adiabatic walls closed by an active layer integrated in a wall (heating wall). To evaluate the performance of the installation and to study the effects of the reflectivity of the PTC mirror, a simulation was performed using TRNSYS software. We noticed that the installation is more profitable during the month of
January for the Errachidia site and the PTC efficiency reaches 0.41 for the three months of heating for a mirror reflectivity of 0.6 . The analysis of the effects of the different system parameters on the performance of its operation shows that the reflectivity of the mirror has a significant influence on the PTC efficiency. However, the efficiency has improved, on average, from 0.41 to 0.63 when the collector reflectivity coefficient increases from 0.6 to 0.9 during the three months of heating.

\section{References}

1. F. Mehdaoui, M. Hazami, A. Messaouda, A. Guizani, Performance analysis of two types of Solar Heating Systems used in buildings under typical North-African climate (Tunisia), Applied Thermal Engineering 165 (2020) 114203.

2. M. Fan, H. Liang, S. You, H. Zhang, B. Yin, X. Wu, Performance analysis of a solar heating system with the absorption heat pump and oil/water heat exchanger, Energy Procedia 142 (2017) 97-104.

3. Q.F. Chen, Z.X. Yuan, Z.Q. Guo, Y. Zhao, Practical performance of a small PTC solar heating system in winter, Solar Energy 179 (2019) 119-127.

4. I. Sobhy, A. Brakez, B. Benhamou, Energy performance and economic study of a solar floor heating system for a Hammam, Energy and Buildings 141 (2017) 1-49.

5. F. Yang, J. Liu, Q. Sun, L. Cheng, R. Wennersten, Simulation analysis of household solar assistant radiant floor heating system in cold area, Energy Procedia 158 (2019) 631-636.

6. Z. Tian, B. Perers, S. Furbo, J. Fan, Annual measured and simulated thermal performance analysis of a hybrid solar district heating plant with flat plate collectors and parabolic trough collectors in series, Applied Energy 205 (2017) 417-427.

7. S. Sobhansarbandi, U. Atikol, Performance of Flat-Plate and Compound Parabolic Concentrating Solar Collectors in Underfloor Heating Systems, Journal of Solar Energy Engineering 137 (2015) 034501-1-5.

8. M. Halimi, I. Outana, A. El Amrani, J. Diouri, C. Messaoudi, Prediction of captured solar energy for different orientations and tracking modes of a PTC system: Technical feasibility study (Case study: South eastern of MOROCCO), Energy Conversion and Management 167 (2018) 21-36.

9. M. Halimi, I. Outana, J. Diouri, A. Amrani, C. Messaoudi, Experimental investigation of absorbed flux circumferential distribution of an absorber with U-pipe tube exchanger for Parabolic Trough Collectors, Applied Thermal Engineering 129 (2018) 1230-1239.

10. L. Li, X. Liu, T. Zhang, Performance Analysis and Instant/delayed Characteristics of a Solar Heating System Used in Cold Regions, Journal of Building Engineering, 2020.

11. Z. Yin, L.Enshen, Z. Xinhui, J. Zhenghao, L. Qinjian, L. Fei, M. Yang, Combined solar heating and air-source heat pump system with energy storage: thermal performance analysis and optimization, Procedia Engineering 205 (2017) 4090-4097.

12. L. Yanhua, H. Wengang, Y. Hongwen, Z. Jian, L. Mingxin, Performance and economic evaluation of evacuated tube solar collector with auxiliary electric heater for rural heating, Energy Procedia 158 (2019) 186-191.

13. F. Mehdaoui, M. Hazami, N. Naili, A. Farhat, Energetic performances of an optimized passive Solar Heating 
Prototype used for Tunisian buildings air-heating application, Solar Energy 206 (2020) 935-961.

14. J.A. Duffie, W.A. Beckman, Solar Engineering of Thermal Processes; Published by J. Wiley and Sons, 1991. 